\title{
Legitimacy and the Transatlantic Management of Crisis
}

\section{Erik Jones *}

The United States-led coalition in Iraq is suffering from a crisis of legitimacy. The evidence is everywhere around us. It can be seen in the decision by incoming Spanish Prime Minister José Luis Rodriguez Zapatero to withdraw his country's forces from Iraq as soon as possible. ${ }^{1}$ It can be read in the growing British popular support for an independent European foreign policy, in the decline of German and French popular support for the Bush Administration's "War on Terror," and in the large percentages of respondents across Europe who question the sincerity of American efforts to reduce international terrorism. ${ }^{2}$ Word of the crisis is on the lips of almost every European politician, and it is in the pages of almost every major newspaper or journal published on either side of the North Atlantic. ${ }^{3}$

But is this really a crisis? If so, should we accept that it is a crisis of legitimacy? The problem is that there is an argument for every piece of evidence. Zapatero could be accused of abandoning his allies, giving in to terrorists, or bowing to ill-informed or misguided public opinion. British Prime Minister Tony Blair could be blamed for bungling public relations, particularly on the issue of weapons of mass destruction, but more generally in his communication of the case for war. Meanwhile, political elites in France and Germany could be accused of playing upon anti-Americanism, even as journalists and pundits stoke controversies (and suggest conspiracies) to sell their publications. Of course, such arguments may be false, disingenuous, even mendacious. But if they are true, then it is hard to claim that there is a crisis of legitimacy. It may even be difficult to accept that we are facing a real crisis at all.

At the bottom of all this, what really matters is our sense of legitimacy and of the importance of legitimacy to the management of an actual, physical, violent, and potentially explosive crisis situation like that found in Iraq today. There is much rhetoric surrounding the concept of legitimacy, but there is an underlying reality to the concept as well. Only by grasping that reality can we begin to apprehend the problems that are besetting the U.S.-led coalition in Iraq and the solutions that must be pursued by the Bush Administration and its allies in Europe.

\section{Theoretical Legitimacy}

The concept of legitimacy is easier to invoke than to understand. The problem is not that we are unfamiliar with the meaning of the term; rather, it is that the term has so

* Erik Jones, Chatham House.

1 Financial Times, 19 April 2004.

2 "A Year after War with Iraq: Mistrust of America in Europe Ever Higher, Muslim Anger Persists-A Nine-Country Survey," The Pew Global Attitudes Project (Washington, D.C.: The Pew Research Center for the People and the Press, 16 March 2004).

3 See, for example, Robert Kagan, "America's Crisis of Legitimacy," Foreign Affairs 83:2 (March/April 2004): 65-88. 
many meanings that are only subtly different from one another. To give an example, we might think about breaking up the concept along two dimensions, with a normativepositive dichotomy on one side, and a means-ends dichotomy on the other. An act of state can be legitimate either because it is "right" or because it is accepted, and it can be judged for how it is undertaken or for what it has achieved. When we are talking about legitimacy, we could be talking about any possible combination of these dimensions, we could be focusing only on one without regard to the other, or we could be giving equal weight to the universe of possibilities as a whole (see Fig. 1).

\begin{tabular}{|c|c|c|}
\hline & Means & Ends \\
\hline Normative & Moral measures & Moral outcomes \\
\hline Positive & Accepted measures & Accepted outcomes \\
\hline
\end{tabular}

Figure 1: Shades of 'Legitimacy.'

Beneath this problem of meaning lies the problem of judgment. Any concept of legitimacy necessarily refers to the perceptions of some political agent. An act of state is only legitimate if it is perceived to be legitimate. The problem of judgment is one of arriving at agreement on who is the appropriate judge. Here it is helpful to use an example in order to avoid obscuring real-world complexity with metaphysical abstraction. Who is the best judge of the United States' policies in Iraq, other states or "public opinion"? If it is other states, then should we focus on the "willing," the "unwilling," or the "opposed"? If it is public opinion, is it limited to the American public, should we consult the opinions of other countries, or should we rather focus attention on the Iraqis themselves? Moreover, who is to say that the choice of political agents to act in judgment is not itself subject to considerations of legitimacy? For example, who is to say that Spanish public opinion is somehow irrelevant to consideration of the legitimacy of the policies of the United States?

Finally, the two problems of meaning and judgment are concatenated. Political actors must first adopt a standard for legitimacy before they can pass judgment. Thus, different groups may hold to different standards, and therefore make different judgments, even where all parties agree on the objective nature of the facts. Indeed, this is largely where we find ourselves today in Iraq. The problem is not that anyone has a radically different perception of the reality of the events as they are unfolding. Rather, it is that different groups are keying on different details, applying different standards, and coming to different conclusions. There is no mystery here. If anything, it is hard to imagine how all the parties would wind up with the same interpretation of the same events. Put another way, legitimacy — at least as it is understood here-seems uniquely prone to controversy. And where controversy is ubiquitous, it is hard to equate such controversy with crisis. 


\section{Practical Legitimacy}

But there is a crisis brewing over Iraq, and that crisis is one of cooperation. Whether we speak of civil disorder within the country itself, the splintering of the "coalition of the willing," the growing rebelliousness of back-bench politicians in Britain, or the inability to agree on a workable United Nations (UN) mandate, it is clear that cooperation is becoming more difficult, and that this difficulty in cooperation is becoming ever more detrimental to the effectiveness of the U.S.-led coalition and of American strategy. This breakdown in cooperation is bringing us to "the point of time when it is to be decided whether any affair or course of action must go on, or be modified or terminated; the decisive moment; the turning point." ${ }^{, 4}$ In other words, we are approaching a crisis.

The point to realize is that this crisis of cooperation is not merely symptomatic of a crisis of legitimacy. The breakdown of cooperation is the crisis of legitimacy, practically understood. To accept this point, however, it is necessary to turn away from theoretical notions of legitimacy and to embrace the concept as an expression of sociological reality. In the Weberian sense, the "legitimacy" of a political authority is its ability to engender obedience or, somewhat more loosely, cooperation. ${ }^{5}$ Later writers, like Seymour Martin Lipset and Fritz Scharpf, have added a few more wrinkles to this Weberian notion of legitimacy - by extending it to different types of judgment or measures of acceptance - but all remain committed to the necessary link to obedience or cooperation. Moreover, they also retain the Weberian distinction between legitimacy and coercion. The use of force may encourage obedience or cooperation, but even an overwhelming application of force cannot ensure that either obedience or cooperation will be the outcome.

This notion of legitimacy is practical because it helps to narrow the effective diversity of meaning and judgment outlined above. What does legitimacy mean? It means whatever works to achieve obedience or cooperation. Who is the appropriate judge of this legitimacy? The judgments of any actors whose obedience or cooperation is necessary to ensure (or facilitate) the success of state action should be considered appropriate. As a practical point, legitimacy does and should mean different things, depending upon the audience addressed. There can be no one standard when there is more than one group sitting in judgment whose opinions matter for the success of the policy.

\section{Cooperation and Coercion}

Of course, legitimacy is not the only source of obedience or cooperation. Coercion works as well. The U.S.-led coalition can assert its authority against all forms of insurgency in Iraq, the Bush Administration can cajole its allies into staying the course, and the Blair government can use its whips against back-benchers. However, the problem with coercion is that it is subject to judgment. In cases where such judgments can have

4 This is the 1913 Webster's Dictionary definition of "crisis."

5 Max Weber, The Theory of Social and Economic Organization, edited and with an introduction by Talcott Parsons (New York: The Free Press, 1997), 324. 
no impact on the effectiveness of state action, then they may be viewed as irrelevant. However, where such judgments matter, they cannot be so easily ignored. Popular opposition to the war in Iraq can engender opposition within the "coalition of the willing." Such opposition can also fuel anti-American sentiment in a way that makes it more difficult for the United States to meet with cooperation in other areas as well.

No matter what the argument is for explaining why this opposition has emerged, the fact that opposition exists is problematic enough. Whether the Bush Administration has acted in a manner that is right or wrong, whether its actions are moral or legal, is not important. What matters is whether Bush Administration assertions can convince different groups or actors to change their view of American policy. Such affective change cannot be coerced, but it is necessary to encourage future cooperation.

Moreover, such affective judgments are centrally significant for the transatlantic management of crisis. The United States and its European allies must find a formula for cooperation in crisis management, a formula that must be acceptable to all parties. There is no sense in appealing to a priori principles about national interests or reasons of state unless there is reason to believe that such appeals will find a receptive audience with all who stand in judgment. Whatever the personal views of any given administration, practical legitimacy is a question of acceptability, not right or wrong.

Within any formula for transatlantic crisis management, the governments of Europe and the United States must give due attention to "winning the hearts and minds" of those groups involved in the conflict. This is not some clever strategy held over from the Kennedy Administration's early involvement in Vietnam. Rather, it is the essence of legitimacy. Without it, the governments of Europe and the United States must accept the inevitability of having to use coercion to ensure cooperation and of facing the political judgments - both domestic and foreign - that such coercive actions will inevitably entail.

The alternative of coercion has little appeal outside the extreme case. When the enemy is Saddam Hussein, Al Qaeda, or the Taliban, there may be some sense in fighting to the bitter end. However, most enemies are neither so discretely identifiable nor so comprehensively beyond use or redemption. Slobodan Milosevic may have been an intractable enemy of peace in Europe, but the Serbian people cannot and should not be so easily disregarded. Their cooperation is essential to peace and security in the Balkans, and that cooperation must be made dependent upon perceptions of legitimacy, not upon the threatened use of force.

\section{Conclusion}

The reality underlying the present crisis in Iraq is that multilateral action and nation building reflect two sides of the same coin: legitimacy. However, the legitimacy at issue is practical, not theoretical. If the Bush Administration is to succeed with its policy in Iraq, then it must get the relevant actors, both domestic and international, to agree to cooperate. Such agreement stems from commitment, not coercion. It represents an act of judgment, not a bending of will. Realization of this simple reality will alleviate not only the present crisis, but also the next. 


\section{Bibliography}

Kagan, Robert. "America’s Crisis of Legitimacy." Foreign Affairs 83, no. 2 (2004).

Weber, Max. The Theory of Social and Economic Organization., 1947. 